\title{
AOR
}

Selected Papers of \#AolR2021:

The 22nd Annual Conference of the

Association of Internet Researchers

Virtual Event / 13-16 Oct 2021

\section{BORED GHOSTS AND ANXIOUS TEXT GAMES: HOW DATING APPS ALGORITHMICALLY CHANNEL THE DESIRE FOR INTIMACY INTO ANXIOUS ENGAGEMENT}

\author{
Gregory Narr \\ NA
}

Dating apps have been characterized as fostering superficial hookups and exacerbating the toxicity of hookup culture because users must decide with whom to meet primarily by looking at photos (David \& Cambre, 2016; Shaw, 2016; Thompson, 2018). Dating apps are probably not the vast hookup factories they are often depicted as (Carpenter \& McEwan, 2016; Enomoto et al., 2017; Hobbs et al., 2016; LeFebvre, 2018). But their popularity seems to point to a shift in the locus of power away from what Michel Foucault referred to as entrepreneurs of themselves (2010), with affective engagement online seeming to be generated from disappointment and anxiety rather than a market mentality (Fisher, 2018; Heino et al., 2010; Illouz, 2007; Kendall, 2018).

This argument is based on two key findings from a thematic analysis of 50 in-depth interviews of online daters, many of whom made the transition from OkCupid's website to the popular swipe-based dating apps of Tinder and Bumble (Guest et al., 2012). I used the "media go-along" method for these interviews, asking my respondents questions that arose as I watched them navigate their dating apps (Jørgensen, 2016). The first finding indicates that my respondents began using dating apps because they wanted to engage in intimate exchanges to get to know their matches, something they felt the elaborate essays on OkCupid rendered redundant. The second finding indicates that instead of intimacy they encountered anxious text games exacerbated by the widespread practice of ghosting on dating apps. And while they considered ghosting to be inconsiderate and nonsensical, they admitted to ghosting matches that they became bored with. These findings help to flesh out how particular feelings, moods, and modes of subjectivity are cultivated by the distinct algorithms dating platforms employ, contributing to our understanding of what many following Tiana Buchar (2017) have called algorithmic imaginaries. While much research has uncovered how online daters feel about the algorithmic recommender systems employed by the platforms they use (Parisi \& Comunello, 2020; Sharabi, 2020; Wang, 2020), the algorithmic imaginaries of dating platform users have not been explicitly compared.

Suggested Citation (APA): Narr, G. (2021, October). Bored Ghosts and Anxious Text Games: How Dating Apps Algorithmically Channel the Desire for Intimacy into Anxious Engagement. Paper presented at AolR 2021: The 22nd Annual Conference of the Association of Internet Researchers. Virtual Event: AolR.

Retrieved from http://spir.aoir.org. 
The matching algorithms of dating websites like OkCupid are generally devised to allow users to home in on compatible matches by deliberately refining their search criteria. They thus seem devised to cultivate entrepreneurial subjects looking to rationally optimize their intimate relationships (Heino et al., 2010; Illouz, 2007). The recommender systems of the most popular dating apps, on the other hand, are calibrated from affective patterns of engagement like swiping and messaging rates. They thus seem to update dating protocols in a way that dovetails with the shift to affect that many have argued is central to algorithmic media (Clough, 2018; Hansen, 2015; Sampson, 2016). Tinder and Bumble also clearly limit "attractive" profiles and matches in order to get users to pay for them while privileging users that receive lots of matches and texts (Courtois \& Timmermans, 2018; Fellizar, 2015; Powering Tinder, 2019). I argue that this is likely to create a feedback loop where ghosting exacerbates the anxiety users feel while texting each other. While dating apps seem to render searches for intimacy fraught with anxiety and substantial connections hard to find, they are well-calibrated to the exigencies of platform capitalism, where social relations are as likely to be sold as things, especially when they vanish as quickly as they appear, like ghosts.

\section{References}

Bucher, T. (2017). The algorithmic imaginary: Exploring the ordinary affects of Facebook algorithms. Information, Communication \& Society, 20(1), 30-44. https://doi.org/10.1080/1369118X.2016.1154086

Carpenter, C. J., \& McEwan, B. (2016). The players of micro-dating: Individual and gender differences in goal orientations toward micro-dating apps. First Monday, 21(5). https://doi.org/10.5210/fm.v21i5.6187

Clough, P. T. (2018). The User Unconscious: On Affect, Media, and Measure (1 edition). Univ Of Minnesota Press.

Courtois, C., \& Timmermans, E. (2018). Cracking the Tinder Code: An Experience Sampling Approach to the Dynamics and Impact of Platform Governing Algorithms. Journal of Computer-Mediated Communication, 23(1), 1-16. https://doi.org/10.1093/jcmc/zmx001

David, G., \& Cambre, C. (2016). Screened Intimacies: Tinder and the Swipe Logic. Social Media + Society, 2(2), 2056305116641976. https://doi.org/10.1177/2056305116641976

Enomoto, C., Noor, S., \& Widner, B. (2017). Is Social Media to Blame for the Sharp Rise in STDs? Social Sciences, 6(3), 78. https://doi.org/10.3390/socsci6030078

Fellizar, K. (2015, August 11). Bumble's New “VIBee” Feature Rewards The Good Men Out There, Plus More Dating Apps With Unique Features. /articles/103615bumbles-new-vibee-feature-rewards-the-good-men-out-there-plus-more-datingapps-with-unique 
Fisher, M. (2018). K-punk: The Collected and Unpublished Writings of Mark Fisher (D. Ambrose, Ed.; New edition edition). Repeater.

Foucault, M. (2010). The Birth of Biopolitics: Lectures at the Collège de France, 1978-1979 (Reprint edition). Picador.

Guest, G., MacQueen, K. M., \& Namey, E. E. (2012). Applied Thematic Analysis. SAGE.

Hansen, M. B. N. (2015). Feed-Forward: On the Future of Twenty-First-Century Media. University Of Chicago Press.

Heino, R. D., Ellison, N. B., \& Gibbs, J. L. (2010). Relationshopping: Investigating the market metaphor in online dating. Journal of Social and Personal Relationships, 27(4), 427-447.

Hobbs, M., Owen, S., \& Gerber, L. (2016). Liquid love? Dating apps, sex, relationships and the digital transformation of intimacy. Journal of Sociology, 1440783316662718. https://doi.org/10.1177/1440783316662718

Illouz, E. (2007). Cold Intimacies: The Making of Emotional Capitalism (1 edition). Polity.

Jørgensen, K. M. (2016). The media go-along: Researching mobilities with media at hand. MedieKultur: Journal of Media and Communication Research, 32(60), 18 p.-18 p. https://doi.org/10.7146/mediekultur.v32i60.22429

Kendall, T. (2018). "\#BOREDWITHMEG”: Gendered Boredom and Networked Media. New Formations: A Journal of Culture/Theory/Politics, 93(93), 80-100.

LeFebvre, L. E. (2018). Swiping me off my feet: Explicating relationship initiation on Tinder. Journal of Social and Personal Relationships, 35(9), 1205-1229. https://doi.org/10.1177/0265407517706419

Parisi, L., \& Comunello, F. (2020). Dating in the time of "relational filter bubbles": Exploring imaginaries, perceptions and tactics of Italian dating app users. The Communication Review, 23(1), 66-89. https://doi.org/10.1080/10714421.2019.1704111

Powering Tinder®—The Method Behind Our Matching. (2019, March 15). Tinder. https://blog.gotinder.com/powering-tinder-r-the-method-behind-our-matching/

Sampson, T. (2016). The Assemblage Brain (1 edition). University of Minnesota Press.

Sharabi, L. L. (2020). Exploring How Beliefs About Algorithms Shape (Offline) Success in Online Dating: A Two-Wave Longitudinal Investigation. Communication Research, 0093650219896936. https://doi.org/10.1177/0093650219896936 
Shaw, F. (2016). "Bitch I Said Hi": The Bye Felipe Campaign and Discursive Activism in Mobile Dating Apps. Social Media + Society, 2(4), 2056305116672889. https://doi.org/10.1177/2056305116672889

Thompson, L. (2018). "I can be your Tinder nightmare": Harassment and misogyny in the online sexual marketplace. Feminism \& Psychology, 28(1), 69-89. https://doi.org/10.1177/0959353517720226

Wang, S. (2020). Calculating dating goals: Data gaming and algorithmic sociality on Blued, a Chinese gay dating app. Information, Communication \& Society, 23(2), 181-197. https://doi.org/10.1080/1369118X.2018.1490796 